\title{
The effects of intravenous infusions of cod-liver and soya-bean oils on the secretion of milk fat in the cow
}

\author{
By J. E. STORRY, A. J. HALL, B. TUCKLEY AND D. MILLARD \\ National Institute for Research in Dairying, Shinfield, Reading
}

(Received 25 fuly 1968-Accepted 26 September I968)

\begin{abstract}
1. The effects of intravenous infusions of emulsified cod-liver oil, Ethive (British Codliver Oils (Hull \& Grimsby) Ltd; ethyl ester fraction of cod-liver oil rich in polyunsaturated acids) and soya-bean oil on the secretion of milk fat and the composition of blood lipids in the dairy cow were investigated.

2. Soya-bean oil increased the yield of total fat, by increasing the secretion of unsaturated $\mathrm{C}_{18}$ acids in milk and also increased the proportions of oleic and linoleic acids in the blood plasma triglycerides.

3. Cod-liver oil and Ethive both decreased the yield of total fat and the yields of $\mathrm{C}_{14}$ to $\mathrm{C}_{18}$ acids but had no effect on the yields of $\mathrm{C}_{4}$ to $\mathrm{C}_{12}$ acids in milk. Although the emulsions contained considerable quantities of $C_{20}$ to $C_{22}$ acids, which were incorporated into the blood plasma triglycerides, these acids were not secreted in the milk fat.

4. It is concluded that, if the polyunsaturated $C_{20}$ and $C_{22}$ acids in cod-liver oil are not hydrogenated in the rumen before their absorption from the digestive tract, they can act directly on the mammary gland, possibly through the inhibition of lipoprotein lipase, to reduce the secretion of long-chain acids in milk. In addition, cod-liver oil may have an indirect effect, through changed volatile fatty acid production in the rumen, on the secretion of short-chain acids in milk.
\end{abstract}

Although it is well established that the feeding of cod-liver oil to dairy cows reduces the content and yield of fat in milk, the factors responsible are not fully known. The addition of cod-liver oil to the diet has been shown to change fermentation in the rumen to a pattern characterized by increased proportions of propionic and valeric acids and decreased proportions of acetic and butyric acids (Shaw \& Ensor, 1959; Nottle \& Rook, 1963; Nicholson, Cunningham \& Friend, 1963; Varman \& Schultz, 1968) and it is possible that this change in rumen fermentation gives rise to the lower yield of milk fat. Changes in the proportions of volatile fatty acids in the rumen have not always been observed with the feeding of cod-liver oil, however, and an alternative postulation that the polyunsaturated acids of cod-liver oil act directly on the mammary gland in some way to inhibit milk-fat synthesis has been made (Hilditch \& Thompson, 1936; Beitz \& Davies, 1964).

In the present experiments emulsified cod-liver oil was infused into the jugular vein of lactating cows to by-pass the rumen and thus avoid any change in volatile fatty acid production. The effects on the secretion of milk fat and its component acids are compared with the effects of similar infusions of emulsified soya-bean oil.

\section{EXPERIMENTAL}

Lactating Friesian cows receiving a diet of hay and concentrates balanced for milk production were given continuous intravenous infusions of either soya-bean or cod-liver oil emulsions. The soya-bean oil emulsion (Intralipid; Paines \& Byrne, 
Greenford, England) was given at the daily rate of $500 \mathrm{~g}$ oil for 2 days. The cod-liver oil emulsions were prepared in the laboratory as previously described (Storry, Tuckley \& Hall, I969) from either unfractionated cod-liver oil or an ethyl ester fraction of cod-liver oil rich in polyunsaturated acids (Ethive; British Codliver Oils (Hull \& Grimsby) Ltd), both specially prepared to have a low peroxide content. The cod-liver oil and Ethive emulsions were infused at the daily rate of $400 \mathrm{~g}$ for 3 days. Two experiments were carried out with each emulsion and the infusion periods were preceded and followed by control periods of 2 and 6 days respectively.

Composite samples representing the milk secreted over I-day periods were prepared and used for the determinations of milk fat content by the Gerber method (British Standards Institution, I955) and for the fatty acid composition of milk fat (Storry, Rook \& Hall, 1967 ). At $12.00 \mathrm{~h}$ on each day of the experiment samples of blood were taken through a cannula situated in the jugular vein opposite to that used for the infusion, and the individual lipid classes in blood plasma were determined by thin-layer chromatography as previously described (Storry et al. 1969). The fatty acid composition of the plasma triglycerides was determined by gas-liquid chromatography of the methyl esters with a Perkin Elmer model Fir gas chromatograph in the experiments with soya-bean oil (Storry et al. 1967) and a Pye Argon gas chromatograph with columns 10\% Apiezon L on I00-120 mesh acid-alkali washed celite at $230^{\circ}$ in the experiments with cod-liver oil and Ethive.

\section{RESULTS}

The fatty acid composition of the emulsions is given in Table I which shows that the soya-bean oil, cod-liver oil and Ethive emulsions contained respectively o, 30 and $66 \%$ of polyunsaturated $\mathrm{C}_{20}$ to $\mathrm{C}_{22}$ acids. The soya-bean oil emulsions were readily accepted by the animals and produced no obvious signs of stress but the emulsions of cod-liver oil and Ethive initially produced a rise of $1 \cdot 7-2 \cdot 8^{\circ}$ in body temperature and

\begin{tabular}{|c|c|c|c|}
\hline Fatty acid* & Soya-bean oil & Cod-liver oil & Ethive \\
\hline $\mathrm{I}_{4}: 0$ & - & $2 \cdot 9$ & - \\
\hline $16: 0$ & 12.8 & 10.6 & 0.7 \\
\hline $16: 1$ & - & 9'I & $6 \cdot 7$ \\
\hline $18: 0$ & $4 \cdot 9$ & $2 \cdot 3$ & - \\
\hline I8:I & 18.0 & $24 \cdot 6$ & $7 \cdot 4$ \\
\hline $18: 2$ & $54 \cdot 2\}$ & & 6.0 \\
\hline $18: 3$ & $9 \cdot 2\}$ & 37 & \\
\hline r8:4 & - & - & $9 \cdot 9$ \\
\hline $20: 0$ & - & - & $I_{4}$ \\
\hline $20: 1$ & - & $10 \cdot 0$ & - \\
\hline $20: 4$ & - & $\mathrm{I} \cdot 4$ & $3 \cdot 3$ \\
\hline $20: 5$ & -- & $12 \cdot 8$ & $33 \cdot 5$ \\
\hline $22: 1$ & - & $5 \cdot 5$ & - \\
\hline $22: 4$ & - & 1.5 & - \\
\hline $22: 5$ & - & $2 \cdot 4$ & $4 \cdot 7$ \\
\hline $22: 6$ & - & $12 \cdot 3$ & $24 \cdot 4$ \\
\hline
\end{tabular}

* Number of carbon atoms and number of double bonds (Farquhar, Insull, Rosen, Stoffel \& Ahrens, I 959). 
increased respiration rate approximately $7 \mathrm{~h}$ after the beginning of the infusion. These signs quickly subsided if the infusion was stopped and did not recur when the infusion was started again. Since all the emulsions were of similar basic chemical composition and microscopically appeared to be equally well emulsified the initial pyrogenic reaction to cod-liver oil and Ethive emulsions may have been related to their content of polyunsaturated $\mathrm{C}_{20}$ to $\mathrm{C}_{22}$ acids, which are not normal constituents of plasma triglycerides in the cow.

Similar results were obtained with both animals infused with the same emulsion and the values given represent the mean for the two experiments. As there were carry-over effects from the infusions, values for the first and last 3 days of the postinfusion period are given separately.

\section{Effect of infusions on milk secretion}

Yield of milk and milk fat (Table 2). Soya-bean oil had little effect on the yield of milk whereas cod-liver oil and Ethive tended to depress milk yield. The depression in milk yield was, however, confined to the first milking on the Ist day of the infusion

Table 2. Effect of intravenously infused soya-bean oil, cod-liver oil and Ethive emulsions on the yields of milk and milk fat and on the fat content of cow's milk

\begin{tabular}{|c|c|c|c|c|}
\hline \multirow[b]{2}{*}{ Treatment } & \multirow[b]{2}{*}{ Pre-infusion } & \multirow[b]{2}{*}{ Infusion } & \multicolumn{2}{|c|}{ Post-infusion } \\
\hline & & & Days $1-3$ & Days 4-6 \\
\hline \multicolumn{5}{|c|}{ Milk yield (kg/day) } \\
\hline $\begin{array}{l}\text { Soya-bean oil } \\
\text { Cod-liver oil } \\
\text { Ethive }\end{array}$ & $\begin{array}{l}13 \cdot 1 \\
19 \cdot 3 \\
16 \cdot 3\end{array}$ & $\begin{array}{l}12.8 \\
18.3 \\
14.6\end{array}$ & $\begin{array}{l}12.7 \\
19 \cdot 9 \\
16.8\end{array}$ & $\begin{array}{l}12 \cdot 2 \\
19 \cdot 4 \\
16 \cdot 4\end{array}$ \\
\hline \multicolumn{5}{|c|}{ Milk fat (\%) } \\
\hline $\begin{array}{l}\text { Soya-bean oil } \\
\text { Cod-liver oil } \\
\text { Ethive }\end{array}$ & $\begin{array}{l}4 \cdot 50 \\
3 \cdot 43 \\
3 \cdot 54\end{array}$ & $\begin{array}{l}5 \cdot 25 \\
3 \cdot 47 \\
3 \cdot 37\end{array}$ & $\begin{array}{l}4 \cdot 31 \\
2 \cdot 88 \\
2 \cdot 63\end{array}$ & $\begin{array}{l}4 \cdot 36 \\
3 \cdot 36 \\
3 \cdot 54\end{array}$ \\
\hline \multicolumn{5}{|c|}{ Milk fat yield (g/day) } \\
\hline $\begin{array}{l}\text { Soya-bean oil } \\
\text { Cod-liver oil } \\
\text { Ethive }\end{array}$ & $\begin{array}{l}589 \\
672 \\
579\end{array}$ & $\begin{array}{l}672 \\
650 \\
502\end{array}$ & $\begin{array}{l}546 \\
584 \\
45^{8}\end{array}$ & $\begin{array}{l}528 \\
657 \\
595\end{array}$ \\
\hline
\end{tabular}

period and was associated with the initial pyrogenic reaction to the cod-liver oil and Ethive emulsions. The content and yield of milk fat were increased with the infusion of soya-bean oil and decreased with the infusions of cod-liver oil and Ethive. The effects of cod-liver oil and Ethive were most marked during the first 3 days of the post-infusion period and the effect was greater with Ethive than with cod-liver oil.

Yields of fatty acids in milk. The effects of soya-bean oil, cod-liver oil and Ethive on the yields of the individual fatty acids in milk are given in Table 3 . Soya-bean oil increased the yields of unsaturated $\mathrm{C}_{18}$ acids thus confirming earlier experiments where cottonseed oil, which has a similar fatty acid composition to soya-bean oil, was infused into cows (Tove \& Mochrie, I963; Storry \& Rook, 1964). Although the 
i 76 J. E. Storry, A. J. Hall, B. Tuckley and D. Millard i 969 soya-bean oil contained some palmitic and stearic acids, the yields of these acids in milk were not increased.

Cod-liver oil and Ethive both decreased the yields of $\mathrm{C}_{14}$ to $\mathrm{C}_{18}$ acids in spite of the fact that appreciable quantities of these acids were contained in the emulsions. Furthermore, there was no secretion of $\mathrm{C}_{20}$ to $\mathrm{C}_{22}$ acids in milk even though the cod-liver oil and Ethive respectively contained 46 and $67 \%$ of these acids.

Table 3. Effect of intravenously infused emulsions of soya-bean oil, cod-liver oil and Ethive on the yields (g/day) of the major fatty acids in cow's milk

\begin{tabular}{|c|c|c|c|c|}
\hline \multirow[b]{2}{*}{ Fatty acid } & \multirow[b]{2}{*}{ Pre-infusion } & \multirow[b]{2}{*}{ Infusion } & \multicolumn{2}{|c|}{ Post-infusion } \\
\hline & & & Days $1-3$ & Days $4-6$ \\
\hline \multicolumn{5}{|c|}{ Soya-bean oil } \\
\hline $4: 0$ & $15 \cdot 2$ & $16 \cdot 2$ & 14.4 & 13.8 \\
\hline $6: 0$ & $12: 4$ & $12 \cdot 9$ & $I I \cdot 6$ & $10 \cdot 1$ \\
\hline $8: 0$ & $7 \cdot 6$ & $8 \cdot 3$ & $12 \cdot 1$ & 70 \\
\hline $10: 0$ & I9. I & $18 \cdot 8$ & $18 \cdot 2$ & $16 \cdot 0$ \\
\hline $12: 0$ & $27 \cdot 3$ & $25^{\circ} 0$ & $27 \cdot 0$ & $24 \cdot 3$ \\
\hline $14: 0$ & $78 \cdot 3$ & $69 \cdot 5$ & $68 \cdot 3$ & 68.0 \\
\hline $16: 0$ & $201 \cdot 4$ & 180.9 & $172 \cdot 5$ & $\mathrm{I} 74.4$ \\
\hline $16: 1$ & 10.8 & $9 \cdot 0$ & $8 \cdot 4$ & $\begin{array}{r}14.4 \\
10.6\end{array}$ \\
\hline $18: 0$ & $38 \cdot 6$ & 34.9 & $36 \cdot 2$ & $36 \cdot 4$ \\
\hline $18: 1$ & $84 \cdot 6$ & $98 \cdot 4$ & $75 \cdot 1$ & 80.6 \\
\hline $18: 2$ & $6 \cdot 8$ & $97 \cdot 8$ & $30 \cdot 3$ & 10.0 \\
\hline $18: 3$ & - & $18 \cdot 4$ & $2 \cdot 5$ & $\cdots$ \\
\hline \multicolumn{5}{|c|}{ Cod-liver oil } \\
\hline $4: 0$ & $15 \cdot 1$ & 14.0 & 12.4 & I 5.6 \\
\hline $6: 0$ & II.5 & I I 9 & 10.4 & $12 \cdot 2$ \\
\hline $8: 0$ & $9 \cdot I$ & $15^{\circ} 0$ & $9 \cdot 0$ & 9.7 \\
\hline 10:0 & $23 \cdot 8$ & $26 \cdot 6$ & $24 \cdot 3$ & $25 \cdot 3$ \\
\hline $12: 0$ & $38 \cdot 5$ & $41 \cdot 4$ & $37 \cdot 5$ & 39.0 \\
\hline $14: 0$ & $94: 3$ & $92 \cdot 8$ & $88 \cdot 2$ & $91 \cdot 9$ \\
\hline $16: 0$ & $18 I \cdot 7$ & $176 \cdot 4$ & $165 \cdot 2$ & I 74.6 \\
\hline $16: 1$ & 15.0 & 19.6 & 10.3 & $12 \cdot 3$ \\
\hline $18: 0$ & $53 \cdot 6$ & $44 \cdot 5$ & $4 I \cdot 3$ & 53.5 \\
\hline 18:1 & 130.4 & $117 \cdot 8$ & 93.0 & Iro. 7 \\
\hline I $8: 2$ & $6 \cdot 5$ & $8 \cdot 1$ & 6.9 & 6.9 \\
\hline \multicolumn{5}{|c|}{ Ethive } \\
\hline $4: 0$ & $14 \cdot I$ & 10.5 & $9 \cdot 6$ & I 34 \\
\hline $6: 0$ & 10.6 & $9 \cdot 8$ & $8 \cdot 4$ & I I. 6 \\
\hline $8: 0$ & $7 \cdot 9$ & $8 \cdot 6$ & $7 \cdot 4$ & $9 \cdot 8$ \\
\hline IO:0 & $21 \cdot 3$ & $27 \cdot 2$ & $22 \cdot 6$ & $25 \cdot 4$ \\
\hline $12: 0$ & $35 \cdot 4$ & $38 \cdot 2$ & $35 \cdot 6$ & $39 \cdot 1$ \\
\hline $14: 0$ & $84 \cdot 0$ & 78.0 & $72 \cdot 8$ & 85.0 \\
\hline I6:0 & 169.9 & $144^{\circ} 0$ & $129^{\circ} 1$ & 162.4 \\
\hline $16: 1$ & $13 \cdot 1$ & $12 \cdot 6$ & $8 \cdot 9$ & 8.9 \\
\hline $18: 0$ & $4 I \cdot 7$ & $33 \cdot x$ & $32 \cdot 4$ & $48 \cdot 4$ \\
\hline I $8:$ I & $88 \cdot 3$ & $68 \cdot 0$ & $62 \cdot 8$ & 94.8 \\
\hline $18: 2$ & $6 \cdot 4$ & 6.9 & $4 \cdot 8$ & $7 \cdot 1$ \\
\hline
\end{tabular}

\section{Effects of infusions on blood composition}

Plasma lipids ('Table 4). Changes in the concentration of cholesterol esters were relatively small and variable from experiment to experiment. The concentrations of free cholesterol in all the experiments and of phospholipids in the experiments 
with soya-bean and cod-liver oils were increased during the infusions, and in some experiments their concentration remained higher during the post-infusion period. Soya-bean and cod-liver oil both increased the concentration of plasma triglycerides and the higher concentration with cod-liver oil persisted into the post-infusion period. No increase in the plasma triglyceride concentration occurred with the infusion of Ethive and this was probably due to the fact that the acids were in the form of ethyl esters rather than glycerides.

Table 4. Effect of intravenously infused emulsions of soya-bean oil, cod-liver oil and Ethive on the concentration $(\mathrm{mg} / 100 \mathrm{ml}$ ) of lipids in blood plasma of cows

\begin{tabular}{|c|c|c|c|c|}
\hline \multirow[b]{2}{*}{ Treatment } & \multirow[b]{2}{*}{ Pre-infusion } & \multirow[b]{2}{*}{ Infusion } & \multicolumn{2}{|c|}{ Post-infusion } \\
\hline & & & Days $1-3$ & Days 4-6 \\
\hline \multicolumn{5}{|c|}{ Cholesterol ester } \\
\hline Soya-bean oil & I $54^{\circ} 7$ & I $78 \cdot I$ & 190.2 & 198.4 \\
\hline Cod-liver oil & $209 \cdot 0$ & $203 \cdot 3$ & $220 \cdot 3$ & $213 \cdot 3$ \\
\hline Ethive* & $211 \cdot 9$ & 199.5 & $204 \cdot 2$ & $222 \cdot 8$ \\
\hline \multicolumn{5}{|c|}{ Cholesterol } \\
\hline Soya-bean oil & $25 \cdot 0$ & $3 I \cdot 3$ & $29 \cdot 3$ & $3 I \cdot 0$ \\
\hline Cod-liver oil & $28 \cdot 4$ & $34 \cdot 6$ & $28 \cdot 8$ & $27 \cdot 6$ \\
\hline Ethive* & 30.7 & $32 \cdot 6$ & $32 \cdot 9$ & 30.7 \\
\hline \multicolumn{5}{|c|}{ Triglyceride } \\
\hline Soya-bean oil & 10.4 & 15.9 & $6 \cdot 9$ & $7 \cdot 9$ \\
\hline Cod-liver oil & 12.4 & $15 \cdot 5$ & $15^{\circ} 0$ & $13 \cdot 8$ \\
\hline Ethive* & I I 8 & I $1 \cdot 8$ & $12 \cdot 2$ & I $3 \cdot \mathbf{I}$ \\
\hline \multicolumn{5}{|c|}{ Phospholipid } \\
\hline Soya-bean oil & I I $7 \cdot 2$ & $155^{\prime 2}$ & $133 \cdot 5$ & I30.0 \\
\hline Cod-liver oil & I 55.5 & $176 \cdot 1$ & $159^{\circ} \mathrm{I}$ & I 59.4 \\
\hline Ethive* & $166 \cdot 3$ & $\times 57.4$ & $164 \cdot 4$ & I66.7 \\
\hline
\end{tabular}

Fatty acid composition of plasma triglycerides. The effects of the infusions of soya-bean oil, cod-liver oil and Ethive on the fatty acid composition of the plasma triglycerides are given in Table 5. The compositions of the plasma triglycerides were altered towards the composition of the particular emulsion infused and the changes in composition persisted into the post-infusion period.

\section{DISCUSSION}

The decreased secretion of milk fat obtained with the intravenous infusion of cod-liver oil and Ethive clearly demonstrates that these oils can directly reduce milk-fat secretion in some way which is not mediated through a change in volatile fatty acid production in the rumen. The greater decrease in fat secretion obtained with Ethive than with cod-liver oil supports the postulation that this effect is related to the content of polyunsaturated acids in these oils. Also, since soya-bean oil, which contained almost $65 \%$ polyunsaturated $\mathrm{C}_{18}$ acids, increased the secretion of milk fat, it would appear that the milk-fat depressing properties of cod-liver oil and Ethive 
Table 5. Effect of intravenously infused emulsions of soya-bean oil, cod-liver oil and Ethive on the fatty acid composition ( $\mathrm{g} / \mathrm{I} \circ \mathrm{O} \mathrm{g}$ ) of plasma triglycerides of cows

\begin{tabular}{|c|c|c|c|c|}
\hline \multirow[b]{2}{*}{ Fatty acid } & \multirow[b]{2}{*}{ Pre-infusion } & \multirow[b]{2}{*}{ Infusion } & \multicolumn{2}{|c|}{ Post-infusion } \\
\hline & & & Days $1-3$ & Days $4^{-6}$ \\
\hline \multicolumn{5}{|c|}{ Soya-bean oil } \\
\hline I 2:0 & $I \cdot I$ & 0.5 & $I \cdot 5$ & $I \cdot 4$ \\
\hline I4:0 & 147 & 0.2 & $5^{\circ} 0$ & $5 \cdot 1$ \\
\hline $14: 1$ & $4 \cdot 3$ & $\mathbf{I} \cdot 8$ & $3^{\cdot I}$ & $2 \cdot 9$ \\
\hline $16: 0$ & $22 \cdot I$ & $19^{\circ} \mathrm{I}$ & $24 \cdot 7$ & $26 \cdot 9$ \\
\hline I6:I & $2 \cdot 6$ & $\mathbf{I} \cdot 6$ & 3.0 & $2 \cdot 6$ \\
\hline I $8: 0$ & $33^{\prime} \mathrm{I}$ & $14 \cdot 6$ & $38 \cdot I$ & $3^{8 \cdot I}$ \\
\hline 18: 1 & 13.0 & $21 \cdot 2$ & 15.6 & $16 \cdot 0$ \\
\hline $18: 2$ & I· 4 & $35^{\circ} 4$ & $4^{\cdot 8}$ & $2 \cdot 2$ \\
\hline \multicolumn{5}{|c|}{ Cod-liver oil } \\
\hline I 2:0 & $\mathbf{1} \cdot 6$ & $1 \cdot 2$ & $I \cdot 4$ & $I \cdot 9$ \\
\hline $14: 0$ & $4 \cdot 9$ & $4 \cdot 3$ & $5 \cdot 4$ & $5 \cdot 5$ \\
\hline I $4: \mathrm{I}$ & $2 \cdot 5$ & 0.8 & 0.7 & 0.8 \\
\hline I5:0+ $15: 0$ br & $4 \cdot 0$ & $2 \cdot 6$ & $4 \cdot 4$ & $3 \cdot 9$ \\
\hline $16: 0$ & $30 \cdot 0$ & $23 \cdot 0$ & 30.0 & $30 \cdot 8$ \\
\hline I6: I & $3 \cdot 8$ & 577 & $6 \cdot 7$ & $5 \cdot 0$ \\
\hline I7:0+17:0 br & $2 \cdot 4$ & $2 \cdot 9$ & $2 \cdot 7$ & $2 \cdot 6$ \\
\hline $18: 0$ & $34 \cdot 2$ & 23.9 & $30 \cdot 6$ & $35^{\circ} \circ$ \\
\hline $\begin{array}{l}\text { I } 8: 1, \text { I } 8: 2, \\
\text { I } 8: 3, \text { I } 8: 4\end{array}$ & 15.5 & $15 \cdot 7$ & 13.0 & $11 \cdot 7$ \\
\hline $20: 0$ & 0.3 & 0.6 & 0.5 & 0.3 \\
\hline $20: I$ & - & $I \cdot \mathbf{I}$ & 一 & - \\
\hline $20: 4$ & 0.2 & $\mathrm{I} \cdot 6$ & 0.4 & - \\
\hline $20: 5$ & 0.2 & $9 \cdot 3$ & I.9 & 0.7 \\
\hline $22: I$ & - & 0.9 & - & - \\
\hline $22: 5$ & - & $I \cdot 9$ & 0.7 & 0.3 \\
\hline $22: 6$ & -- & $4 \cdot 4$ & 0.8 & 0.3 \\
\hline \multicolumn{5}{|c|}{ Ethive } \\
\hline $12: 0$ & $2 \cdot 8$ & $2 \cdot 4$ & $x \cdot 6$ & $1 \cdot 7$ \\
\hline $14: 0$ & $7 \cdot 2$ & $7 \cdot 0$ & $5 \cdot 9$ & $5 \cdot 4$ \\
\hline 14: I & 0.9 & 0.8 & 0.8 & 0.6 \\
\hline $\mathrm{I}_{5}: 0+\mathrm{I}_{5}: 0 \mathrm{br}$ & $5 \cdot I$ & $5 \cdot 6$ & 47 & $4 \cdot 2$ \\
\hline $16: 0$ & $3 \mathrm{I} \cdot 4$ & $28 \cdot 9$ & $27 \cdot 5$ & $27 \cdot 4$ \\
\hline $16: 1$ & $3 \cdot 6$ & $7 \cdot 7$ & $6 \cdot 5$ & $4 \cdot 6$ \\
\hline $17: 0+\mathrm{r} 7: 0 \mathrm{br}$ & $2 \cdot 4$ & $3 \cdot 4$ & $2 \cdot 8$ & $2 \cdot 4$ \\
\hline $18: 0$ & $34 \cdot 5$ & $27 \cdot 7$ & $32 \cdot 2$ & 35.5 \\
\hline $\begin{array}{l}18: 1,18: 2 \\
18: 3,18: 4\end{array}$ & II 2 & 10.0 & II 2 & $12 \cdot 7$ \\
\hline $20: 0$ & 0.2 & 0.4 & 0.4 & 0.5 \\
\hline $20: 4$ & -- & 0.5 & 0.6 & 0.5 \\
\hline $20: 5$ & - & $3 \cdot 2$ & $2 \cdot 9$ & $2 \cdot 5$ \\
\hline $22: 5$ & - & 0.7 & $1 \cdot 3$ & $I \cdot 0$ \\
\hline $22: 6$ & 一 & $1 \cdot 0$ & $\mathrm{I} \cdot 3$ & 0.9 \\
\hline
\end{tabular}

are associated specifically with their content of polyunsaturated $\mathrm{C}_{20}$ to $\mathrm{C}_{22}$ acids. Although Ethive was much richer than cod-liver oil in its content of polyunsaturated $\mathrm{C}_{20}$ to $\mathrm{C}_{22}$ acids, the plasma triglycerides from cows infused with Ethive had a lower content of these polyunsaturated acids than the plasma triglycerides from cows infused with cod-liver oil. This apparent discrepancy is due to the fact that the fatty acids in Ethive were given as the ethyl esters which, in the method of thin-layer 
chromatography used for the preparation of the plasma triglycerides, ran slightly ahead of the plasma triglycerides. Although this faster running band of ethyl esters appeared in the plasma lipid samples taken during the infusion they were not included in the plasma triglyceride analysis. The results in Table 8 , however, clearly show that some of the ethyl esters were incorporated by the cow into her plasma triglycerides.

In terms of the individual fatty acids in milk, cod-liver oil and Ethive decreased only the yields of acids with fourteen or more carbon atoms. This restriction of the extraruminal effect of cod-liver oil to the intermediate and long-chain acids in milk is of particular interest in view of the fact that it is these acids which are derived either partly or completely from the triglycerides of the plasma $\beta$-lipoproteins, whereas the yield of the short-chain acids, which are synthesized within the gland from acetate and $\beta$-hydroxybutyrate, were not affected. Normally the fatty acids of the plasma $\beta$-lipoprotein and chylomicron triglycerides are hydrolysed by the action of lipoprotein lipase in the capillary wall before they enter the mammary secretory cells (Linzell, I968) and it is possible that the extraruminal effect of cod-liver oil observed in the present experiments may be related to diminished activity of this enzyme. In this respect it is thus of interest that feeding cod-liver oil to cows has been reported to decrease the uptake of plasma triglycerides by the mammary gland (Varman \& Schultz, I968).

Studies by earlier workers on the effects of feeding cod-liver oil on milk-fat secretion have been limited mainly to changes in the yield of total milk fat and changes in its composition as determined by Reichert Meissl and iodine values. From this earlier work, and in particular from more detailed studies in which individual fatty acids were determined (Hilditch \& Thompson, 1936; Beitz \& Davies, 1964), it would appear that, when cod-liver oil is fed to cows, in addition to a reduced yield of long-chain acids there is also a reduced yield of short-chain acids in milk, but this latter effect was not observed in the present experiments when cod-liver oil was given intravenously. Such an effect on the short-chain acids of milk could conceivably be due to the altered proportions of volatile fatty acids in the rumen which can occur with the feeding of cod-liver oil (Shaw \& Ensor, 1959; Nottle \& Rook, I963; Nicholson et al. 1963; Varman \& Schultz, 1968) and this would account for the fact that the yields of the short-chain acids in the milk were not affected in the present experiments.

Although a direct effect of cod-liver oil on the metabolism of the mammary gland has been demonstrated in the present experiments, the importance of this pathway in the diminished secretion of milk fat which results from the normal feeding of cod-liver oil has not been demonstrated conclusively. For this direct pathway to be of importance under conditions of feeding it would be necessary to assume that polyunsaturated $\mathrm{C}_{20}$ and $\mathrm{C}_{22}$ acids, unlike polyunsaturated $\mathrm{C}_{18}$ acids, are not readily hydrogenated in the rumen before their absorption from the digestive tract. Support for this assumption comes from the fact that the feeding of cod-liver oil reduces the yields of long-chain acids in milk, suggesting, in the light of the present findings, that some of the polyunsaturated $\mathrm{C}_{20}$ and $\mathrm{C}_{22}$ acids pass through to the blood stream 
to act directly on the mammary gland. However, the effect of feeding cod-liver oil on the composition of blood plasma triglycerides is not known, and this aspect is at present being investigated by us.

The cod-liver oil and Ethive emulsions contained considerable quantities of $\mathrm{C}_{20}$ to $\mathrm{C}_{22}$ acids and yet these acids did not appear in the milk. These findings agree with the observations of Beitz \& Davies (I964), but not with those of Hilditch \& Thompson (I936) who found a $5 \%$ increase in the molecular proportions of $\mathrm{C}_{20}$ to $\mathrm{C}_{22}$ acids in milk following the feeding of cod-liver oil. In the present experiments with cod-liver oil and Ethive the plasma triglycerides did contain $\mathrm{C}_{20}$ to $\mathrm{C}_{22}$ acids and it would therefore appear that their uptake by the mammary gland was limited by some factor. Whether this absence of secretion of $\mathrm{C}_{20}$ to $\mathrm{C}_{22}$ acids in milk was merely related to the same factors responsible for the diminished secretion of $C_{14}$ to $C_{18}$ acids (i.e. possible inhibition of lipoprotein lipase activity) or whether it reflected a more specific discrimination by the mammary gland against these $C_{20}$ to $C_{22}$ acids is not known and raises a further subject for study.

We are grateful to Mr S. A. Reed, British Codliver Oils (Hull \& Grimsby) Ltd for supplying samples of special low-peroxide cod-liver oil and Ethive, to Paines \& Byrne Ltd, Greenford, Middlesex for supplying Intralipid, and to Mr A. F. Hamnett and Miss S. Rigby for skilled technical assistance.

\section{REFERENCES}

Beitz, D. C. \& Davies, C. L. (1964). F. Dairy Sci. 47, 1213.

British Standards Institution. (1955). British Standard 696; Part 1, p. 7. London: British Standards Institution.

Farquhar, J. W., Insull, W. Jr, Rosen, P., Stoffel, W. \& Ahrens, E. H. Jr (1959). Nutr. Rev. 17, Suppl. Hilditch, T. P. \& Thompson, H. M. (1936). Biochem. 7. 30, 677.

Linzell, J. L. (r968). Proc. Nutr. Soc. 27, 44.

Nicholson, J. W. G., Cunningham, H. M. \& Friend, D. W. (1963). Can. F. Anim. Sci. 43, 309.

Nottle, M. C. \& Rook, J. A. F. (1963). Proc. Nutr. Soc. 22, vii.

Shaw, J. C. \& Ensor, W. L. (1959). F. Dairy Sci. 42, г 238.

Storry, J. E. \& Rook, J. A. F. (I 964). Biochem. Y. 9I, 27 C.

Storry, J. F., Rook, J. A. F. \& Hall, A. J. (1967). Br. F. Nutr. 21, 425.

Storry, J. E., Tuckley, B. \& Hall, A. J. (1969). Br. F. Nutr. 23 , 157.

Tove, S. B. \& Mochrie, R. D. (1963). F. Dairy Sci. 46, 686.

Varman, P. N. \& Schultz, L. H. (1968). J. Dairy Sci. 51, 968. 